\title{
Mit dem Ball zu den Sternen
}

Erhard Taverna

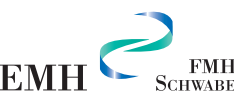

Der Buchtitel hat eine doppelte Bedeutung: Er erzählt die Geschichte eines Fussballstars und erinnert an den Glauben der Mayas, wonach gefallene Krieger als Sterne am Nachthimmel glänzen. Der Roman beginnt mit dem Qualifikationsspiel Honduras gegen El Salvador für die Weltmeisterschaft 1970 und endet eine Generation später mit dem Viertelfinale einer weiteren WM. Die erste Niederlage der Honduraner führte zum berüchtigten Fussballkrieg, der fünf Tage dauerte und 3000 Tote forderte, unter ihnen auch den Vater des Romanhelden. Die zweite Niederlage beendet die steile Karriere des Pablo Moya, Sohn des gefallenen Soldaten, Nationalheld und Stürmer im honduranischen Team.

Der Autor, Alfred Bollinger, schildert den exemplarischen Aufstieg eines jungen Mannes aus dem Armenviertel von Tegucigalpa zum hochbezahlten Profi europäischer Fussballclubs. Strassenszenen Mittelamerikas wechseln mit Einkäufen in der Zürcher Bahnhofstrasse, Trainingsspiele und Matchszenen werden ebenso kenntnisreich beschrieben wie die Eigenschaften der Spieler, die Bräuche der Fans und die Intrigen der Fuss-

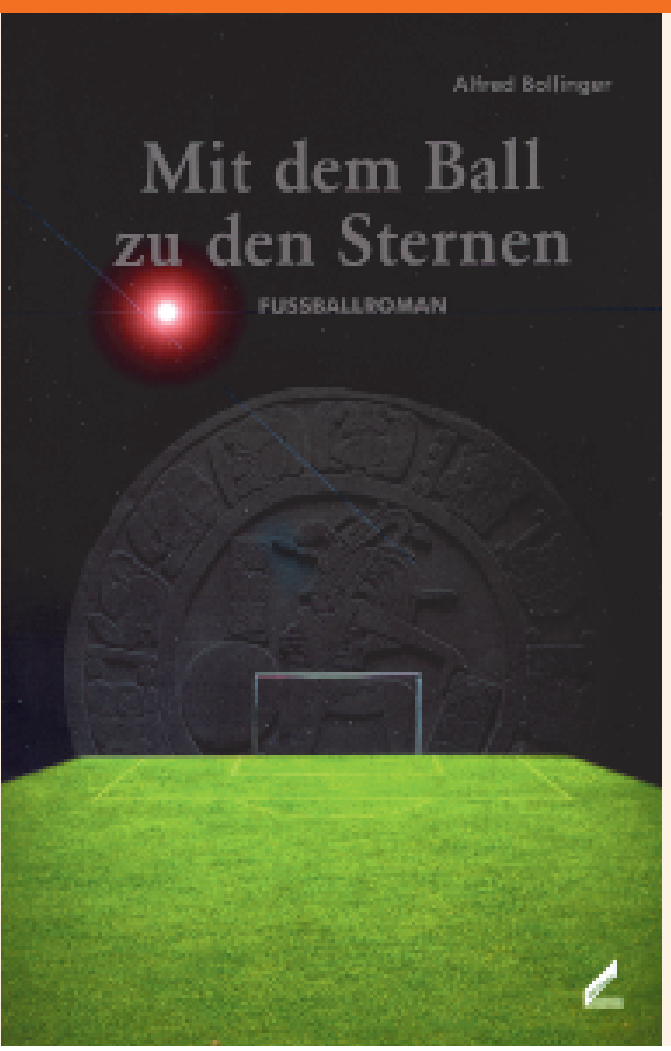

ballfunktionäre. Erstaunlich sind das professionelle Vokabular und ein flexibler Sprachstil, der scheinbar mühelos vom Marktgeschrei der Strassenhändler zur routinierten Sportreportage übergeht und selbst dem komplizierten Liebesleben des Fussballhelden gewachsen ist. Raffiniert sind die Rituale des heutigen Fussballverbandes mit dem Zeremoniell der Mayakämpfer auf dem Ballspielplatz von Copan verwoben, das mit der Opferung eines gefangenen Fürsten endet.

Auf dem Spielplatz wird die kosmische Ordnung wieder hergestellt: Die Fürsten der Unterwelt spielten Fussball mit einem abgetrennten Kopf, die Spieler auf Yukatan mit einem Hartgummiball aus Kautschuk, für die WM 2006 steht der offizielle Polyurethanball, Empa-geprüft, von Adidas bereit. Wer sich einstimmen will in die kommenden Schlachten, der lese den Fussballroman des Kollegen Alfred Bollinger.

- Bollinger A. Mit dem Ball zu den Sternen. Augsburg: Wissner; 2005. 288 Seiten. 


\section{Schundroman}

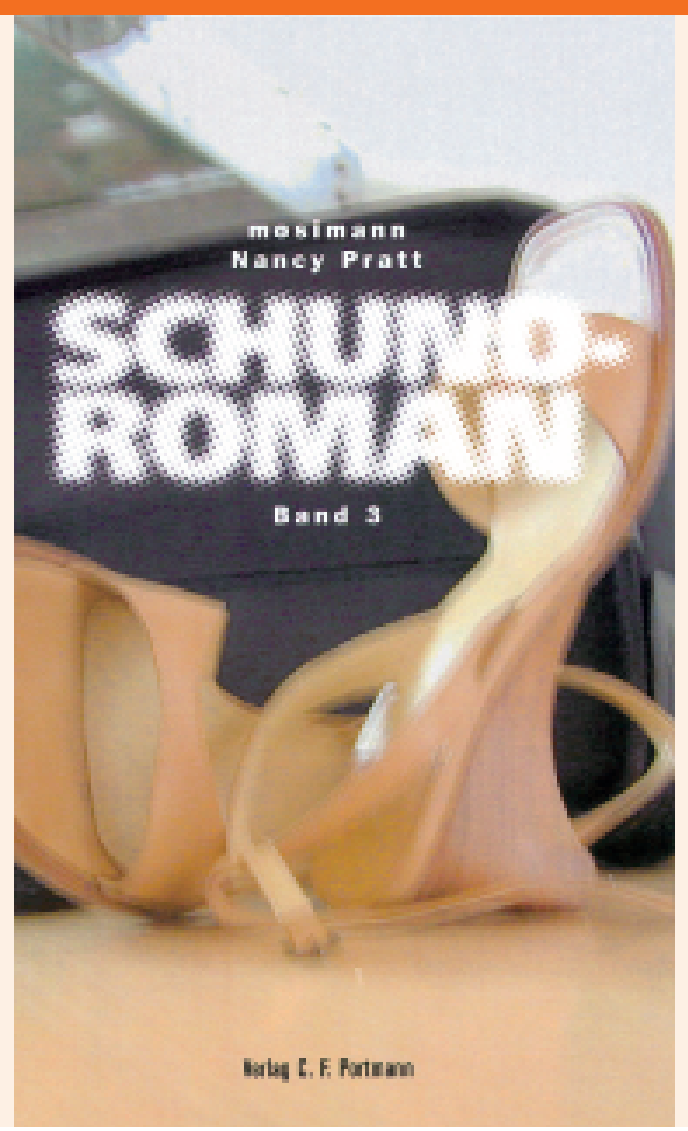

Erhard Taverna

«Was lange währt wird endlich Glut. Und glutheiss kommt sie daher, die Story im dritten Band des Schundromans», so der Autor Edgar Mosimann, Herzchirurg, Südfrankreich- und Thrillerexperte, zu seiner lange erwarteten Fortsetzung. Vielleicht erinnern Sie sich an den Pilotband zur Serie «Schundroman», an Band 2 «Faller in Not», vielleicht auch nicht. Sie alle sind vergnüglich zu lesen, liefern haufenweise Sex and Crime in hochsterilen Operationsräumen und weniger keimfreien Chefbüros. Mosiman ist ein talentierter Barkeeper, der in seinem Cocktail eine Prise Kitsch, mit einem Schuss Blut und anderen Säften, mit einem mörderischen Komplott und einem Schuss Fachzynismus, zu einem deftigen Gebräu jongliert. Selbstironisch berichtet er über den schwierigen Prozess des Krimischreibens und fordert eine geneigte Leserschaft zur Mitarbeit auf, die er mit seinen Zwischenbemerkungen auf den Arm nimmt. Zum Beispiel mit einem
Ratgeber zum Erfolg, inklusive Quiz: «Lassen Sie mich wiederholen: gewöhnen Sie sich differenzierte Wortmeldungen ab. Sprechen Sie bestimmt und mit dümmlicher Selbstüberschätzung. Schrecken Sie nicht zurück vor vulgären Äusserungen.» Einige seiner Romanfiguren beherzigen diese goldenen Regeln. Den weniger Fortgeschrittenen, den Medizinern und CEOs, empfiehlt er sein Schulungszentrum für Spitzenmanager in Châteaudouble, Departement Var. Urteilen Sie selbst, es geht auch ohne Vorkenntnisse der Bände 1 und 2, aber nicht ohne Suchtgefahr. Weiterer Stoff ist geplant: «Das Erbe von Krabbe» (2006), «Swimmingpool für ein Motorrad» (2007) und «Galerie ohne Bild» (2008).

- Mosimann E, Pratt N. Schundroman. Band 3. Erlenbach: Verlag C. F. Portmann: 2005. 209 Seiten. 